\title{
Stress-induced analgesia: Effect of naloxone following cold water swims
}

\author{
RICHARD J. BODNAR, DENNIS D. KELLY, ANGELA SPIAGGIA, \\ CONSTANTINE PAVLIDES, and MURRAY GLUSMAN \\ Department of Behavioral Psychology, New York State Psychiatric Institute, and \\ Department of Psychiatry, Columbia University, New York, New York 10032
}

\begin{abstract}
Rats exposed to novel stressful events subsequently display increased nociceptive thresholds while chronic exposure produces adaptation. The present study investigated whether the analgesia induced by one such stressor, a brief, forced cold-water swim, could be eliminated by an opiate receptor blockade induced by a narcotic antagonist. Naloxone at a dose of $10 \mathrm{mg} / \mathrm{kg}$ was partially able to attenuate stress-induced analgesia, but it had no effect upon normal nociceptive thresholds in unstressed control subjects. That a high dose of naloxone only partially attenuates stress-induced analgesia suggests that this type of analgesia is not identical to that induced by opiates.
\end{abstract}

When first exposed to a stressful event, rats display a transient, yet significant, increase in nociceptive thresholds. Following the initial observation that rats showed increased tail-flick latencies following acute exposure to such severe stresses as inescapable footshock, rotation, or intraperitoneal injections of hypertonic saline (Hayes, Bennett, Newlon, \& Mayer, 1976), a number of other effective stressors have been identified, such as cold water swims (Bodnar, Kelly, \& Glusman, 1978; Bodnar, Kelly, Spiaggia, \& Glusman, 1977), food deprivation (Spiaggia, Bodnar, Kelly, McManus, \& Glusman, 1977), and administration of 2-deoxy-D-glucose, an antimetabolic analogue of glucose, which produces a state of acute glucoprivation (Bodnar, Brutus, Glusman, \& Kelly, 1978).

Given the number and range of novel environmental events that increase nociceptive thresholds, it would seem unlikely that various nonspecific peripheral factors peculiar to the individual stressors could account for the threshold elevations. Further evidence supports this contention. First, whereas acute exposure to either inescapable footshock or cold water swims produces analgesia, chronic exposure over daily sessions leaves nociceptive thresholds unaltered (Akil, Madden, Patrick, \& Barchas, 1976; Bodnar, Kelly, Spiaggia, \& Glusman, 1977; Bodnar, Kelly, Spiaggia, \& Glusman, 1978; Madden, Akil, Patrick, \& Barchas, 1977), suggesting that stress-induced analgesia adapts in much the same manner

R.J.B. was supported by Postdoctoral NIMH Grant 13579. The research was supported by N. Y. S. Health Research Council Grants 922 to R. J. B. and 365 to D. D. K. We thank L. Skaredoff for technical assistance, C. Greenman for manuscript preparation, and Endo Laboratories for their kind donation of the naloxone hydrochloride. Send all correspondence to: Dr. R. J. Bodnar, Department of Behavioral Physiology, New York State Psychiatric Institute, 722 West 168th Street, New York, New York 10032. as autonomic and neuroendocrine stress responses adapt following chronic exposure to stressors (Selye, 1952). Second, with respect to the specific stressor employed in the present experiment, significant core and skin temperature reductions occur following exposure to both acute and chronic cold water swims, but only the former result in analgesia (Bodnar, Kelly, Spiaggia, \& Glusman, 1977, 1978). Third, general activity levels of stressed animals increase at the same rate following both acute analgesic swims and chronic nonanalgesic swims (Bodnar, Glusman, Spiaggia, Brutus, \& Kelly, 1978).

The present study assessed whether stress-induced analgesia might be dependent upon activity in the recently identified endogenous opiate system by blocking the opiate receptor blockade via administration of naloxone, a strong narcotic antagonist. Naloxone has been shown to eliminate completely analgesia induced by systemic or intracerebral administration of morphine (Jacquet \& Lajtha, 1974; Martin, 1967) and to attenuate stimulation-produced analgesia (Akil, Mayer, \& Liebeskind, 1976; Oliveras, Hosobuchi, Redjemi, Guilbaud, \& Besson, 1977; Pert \& Walter, 1976; Yaksh, Yeung, \& Rudy, 1976). In contrast, analgesia induced by inescapable footshock was reported to be unaltered by low $(1-\mathrm{mg} / \mathrm{kg})$ naloxone doses (Hayes et al., 1976) but partially attenuated by moderate $(10 \mathrm{mg} / \mathrm{kg})$ doses (Akil, Madden, Patrick, \& Barchas, 1976). Finally, naloxone has produced only mild or no changes in normal pain sensitivity with some studies reporting reflex hyperanalgesia (Bernston \& Walker, 1977; Frederickson, Burgis, \& Edwards, 1977; Jacob, Tremblay, \& Colombel, 1974) and others reporting unaltered nociceptive thresholds (El-Sobky, Dostrovsky, \& Wall, 1976; Goldstein, Pryor, Otis, \& Larsen, 1976). The present study examined whether analgesia induced by another stressor, cold water swims, could be elimi- 
nated by naloxone, and if so, whether this effect could be attributed to naloxone's effect upon normal nociceptive thresholds.

\section{METHOD}

Twenty-four male Holtzman Sprague-Dawley rats (350$500 \mathrm{~g}$ ) were tested for flinch-jump thresholds using a modification of the Evans (1961) procedure. Testing was carried out in a Plexiglas chamber that had a $30 \times 24 \mathrm{~cm}$ grid floor composed of 14 bars $(.6-\mathrm{cm}$ diam) spaced $1.8 \mathrm{~cm}$ apart. Electric shocks were delivered through the grids by a $60-\mathrm{Hz}$ constant-current shock generator through a 14-pole shock scrambler. Using an ascending method of limits of successively more intense shocks, the flinch threshold was defined in milliamperes as the lowest intensity that elicited a withdrawal of a single paw from the grids. The initial jump threshold was defined as the lowest intensity that elicited simultaneous withdrawal of both hindpaws from the grids. The jump threshold was defined as the lowest of two consecutive intensities that elicited a jump as above. Each trial began with the animal receiving a $300-\mathrm{msec}$ footshock at a current intensity of $.1 \mathrm{~mA}$. Subsequent shocks were increased in equal $.05-\mathrm{mA}$ steps at $20-\mathrm{sec}$ intervals. Following the determination of flinch, initial jump, and jump thresholds on each trial, the current intensity was reset to $.1 \mathrm{~mA}$ for the next trial until 10 trials were completed.

The 24 rats were randomly assigned to four groups of 6 rats each. The first, or control, group underwent daily flinch-jump testing for 5 consecutive days. The second, or naloxone, group was administered a subcutaneous dose of $10 \mathrm{mg} / \mathrm{kg}$ of naloxone (Naloxone Hydrochloride, Endo Labs; $10 \mathrm{mg} / \mathrm{ml}, .9 \%$ saline) $30 \mathrm{~min}$ prior to the first of 5 days of flinch-jump testing. The third, or naloxone-stress, group was administered $10 \mathrm{mg} / \mathrm{kg}$ of naloxone immediately prior to the cold water stress condition, which occurred 30 min prior to the first of 5 days of flinch-jump testing. The fourth, or saline-stress, group was treated identically to the third group, but received only saline.

In the cold water stress condition, each animal was placed in a bath of $2^{\circ} \mathrm{C}$ ice water and forced to swim for $3.5 \mathrm{~min}$. The water was too deep for the animal to stand without being submerged. Between swim exposure and psychophysical testing, the rats were placed in individual cages lined with new spaper.

\section{RESULTS}

Figure 1 shows that, while naloxone failed to alter normal nociceptive thresholds in unstressed animals, it partially attenuated the analgesia induced by cold water swims. Two-way analyses of variance for each nociceptive measure revealed significant effects among the groups [jump: $F(3,40)=23.50, p<.01$; initial jump: $\mathrm{F}(3,40)=11.50, \mathrm{p}<.01$; flinch: $\mathrm{F}(3,40)=4.88, \mathrm{p}<.01]$ and between the experimental (Day 1) and baseline (Day 5) sessions [jump: $\mathrm{F}(1,40)=34.00, \mathrm{p}<.01$; initial jump: $F(1,40)=10.10, p<.01 ;$ flinch: $F(1,40)=8.75$, $\mathrm{p}<.01]$. While baseline sessions across the groups were similar [jump: $F(3,20)=1.41$; initial jump: $F(3,20)=$ .83 ; flinch: $F(3,20)=.48$ ], Scheffé post hoc comparisons showed that cold water swims significantly elevated all nociceptive measures in the saline-stress group [jump: $\mathrm{F}(1,10)=30.47, \mathrm{p}<.01$; initial jump: $\mathrm{F}(1,10)=38.72$, $\mathrm{p}<.01$; flinch: $\mathrm{F}(1,10)=8.74, \mathrm{p}<.05]$. Compared to these saline-stress subjects, naloxone was most effective

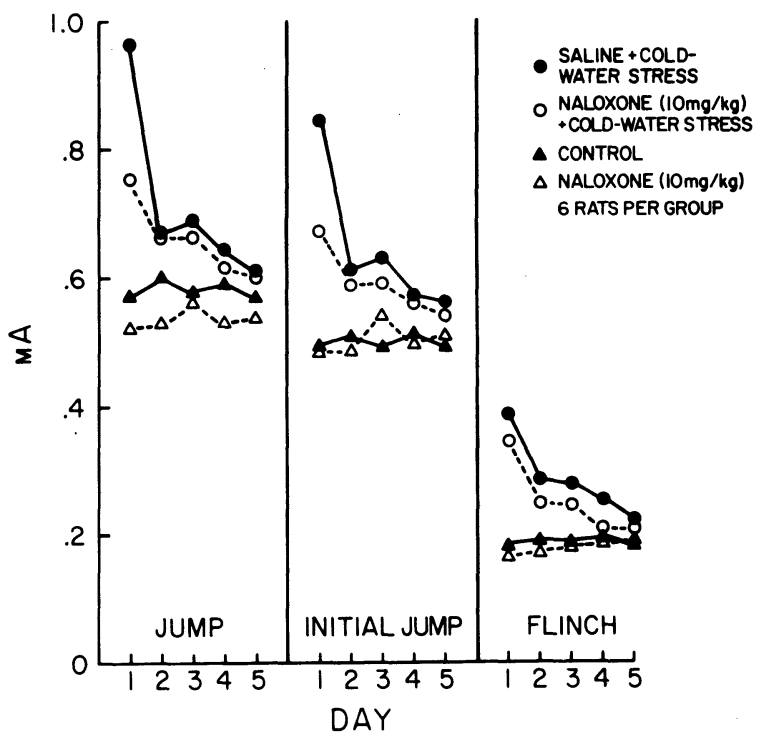

Figure 1: Alterations in flinch-jump thresholds of rats pretreated with naloxone following acute exposure to cold water stress, of similarly stressed rats injected with saline, and of unstressed rats pretreated with naloxone or saline. All experimental manipulations occurred $\mathbf{3 0}$ min preceding the nociceptive test.

in attenuating stress-induced increases in the jump thresholds of the naloxone-stress group $[\mathrm{F}(1,10)=4.39$, $\mathrm{p}<.05]$. It had less pronounced effects upon initial jump thresholds $[F(1,10)=3.41, .10>p>.05]$ and no effect upon flinch thresholds $[\mathrm{F}(1,10)=.18]$. Naloxone's ability to attenuate stress-induced analgesia was not due to its effects upon normal pain thresholds. These measures in the naloxone-alone group were unaffected by drug administration [jump: $F(1,10)=.93$; initial jump: $F(1,10)=.37$; flinch: $F(1,10)=1.49$ ]

Strong individual differences in effectiveness of the single dose of naloxone were observed among the six naloxone-stress rats tested. In four, naloxone markedly reduced stress-induced increases in jump and initial jump thresholds, with Day 1 thresholds comparable to Day 5. The other two naloxone-injected rats responded like the saline-control animals. The differential effectiveness of naloxone among the six rats was not correlated with any other behavioral sign. No such individual differences were noted among the subjects in the naloxone-alone group.

\section{DISCUSSION}

The partial reduction by naloxone of analgesia produced by cold water stress agrees with the Akil, Madden, Patrick, and Barchas (1976) observation that naloxone at the same dose of $10 \mathrm{mg} / \mathrm{kg}$ attenuated analgesia caused by repeated footshock. These investigators also found, as we did, that naloxone's partial effectiveness actually reflected a statistical blend within the experimental group of two binary effects: marked analgesic reversal in some animals and no effect in others. Similar binary effects of naloxone at both 1 and $10 \mathrm{mg} / \mathrm{kg}$ upon stimulation- 
produced analgesia from the periaqueductal midbrain have also been noted (Akil, Mayer, \& Liebeskind, 1976). While such individual differences seem to characterize naloxene's interactions with analgesia induced by cold water stress, footshock, or brain stimulation, this drug has been consistently effective in reversing opiate-induced analgesia (Jacquet \& Lajtha, 1974; Martin, 1967). These findings point to an essential difference between opiate-induced and other types of analgesia.

Several other biochemical and behavioral studies have attempted to link stress-induced analgesia to the activity of endogenous opiates. Recent observations indicate that increased brain opiate receptor binding occurs parallel to the analgesia produced by inescapable footshock (Madden, Patrick, \& Barchas, 1976; Chance, White, Krynock, \& Rosecrans, 1977a, 1977b; Madden et al., 1977). This same stressur at slightly different parameters, however, fails to increase ${ }^{3} \mathrm{H}$-met-enkephalin activity in brain (Fratta, Yang, Hong, \& Costa, 1977) but can increase B-endorphin activity in blood, but not brain (Rossier, French, Rivier, Ling, Guilleman, \& Bloom, 1977). Moreover, Bendorphin and adrenocorticotropin are released concomitantly by the pituitary following injury stress (Guilleman, Vargo, Rossier, Minick, Ling, Rivier, Vale, \& Bloom, 1977). On the other hand, evidence dissociating stress-induced analgesia includes the observations that dorsolateral lesions of the spinal cord which eliminate morphine and stimulation-induced analgesia (Basbaum, Marley, O'Keefe, \& Clanton, 1977) fail to attenuate analgesia induced by inescapable footshock (Price, Hayes, Bennett, Wilcox, \& Mayer, 1976) and that crosstolerance fails to develop between morphine-produced and cold water stressinduced analgesia (Bodnar, Kelly, Steiner, \& Glusman, 1977).

An alternative, though conjectural, explanation for the apparent nonopiate properties of stress-induced analgesia may involve participation of the recently described delta-type opiate receptor for which the enkephalins, but not morphine or naloxone, possess high affinity (Lord, Waterfield, Hughes, \& Kosterlitz, 1977). Thus, an enkephalin-mediated stress-induced response which exerted its analgesic effects exclusively, or predominantly, via protected delta receptors, might be expected to be impervious to naloxone antagonism. Of these two alternatives, the most parsimonious explanation for these results would posit the existence of a parallel nonopiate route of access, or neural input, into that descending bulbospinal system that apparently serves as the final common path for pain inhibition and which may also be accessed through opiate inputs (Mayer \& Price, 1976).

\section{REFERENCES}

Akil, H., Madden, J., Patrick, R. L., \& Barchas, J. D. Stressinduced increase in endogeneous opiate peptides: Concurrent analgesia and its partial reversal by naloxone. In $\mathrm{H}$. W. Kosterlitz (Ed.), Opiates and endogeneous opioid peptides. Amsterdam, North Holland: 1976. Pp. 63-70.

Akil, H., Mayer, D. J., \& Libeskind, J. C. Antagonism of stimulation-produced analgesia by naloxone, a narcotic antagonist. Science, 1976, 191, 961-963.

Basbaum, A. I., Marley, N. J. E., O'Keefe, J., \& Clanton, C. H. Reversal of morphine and stimulus-produced analgesia by subtotal spinal cord lesions. Pain, 1977, 3, 43-56.

BERnston, G. G., \& WALKER, J. M. Effect of opiate receptor blockade on pain sensitivity in the rat. Brain Research Bulletin, 1977, 2, 157-159.

Bodnar, R. J., Brutus, M., Glusman, M., \& Kelly, D. D. Analgesia induced by 2-deoxy-D-glucose, an antimetabolic glucose analogue. Federation Proceedings, 1978, 37.

Bodnar, R. J., Glusman, M., Spiaggia, A.. Brutus, M., \& KELLY, D. D. Attenuation of stress-induced increases in nociceptive thresholds by hypophysectomy. Second World Congress on Pain of the International Association for the Study of Pain, Pain Abstracts, 1978, 1.
Bodnar, R. J., Kelly, D. D., \& Glusman, M. Stress-induced analgesia: Time course of pain reflex alterations following cold water swims. Bulletin of the Psychonomic Society, 1978, 11, 333-336.

Bodnar, R. J., Kelly, D. D., Spiaggia, A., \& Glusman, M. Analgesia produced by cold-water stress: Effect of naloxone. Federation Proceedings, 1977, 36 (3).

Bodnar, R. J., Kelly, D. D., Spiaggia, A., \& Glusman, M. Stress-induced analgesia: Adaptation following chronic cold water swims. Bulletin of the Psychonomic Society, 1978, 11, 337-340.

Bodnar, R. J., Kelly, D. D., Steiner, S. S., \& Glusman, M. Stress-produced analgesia and morphine-produced analgesia: Lack of cross-tolerance. Society Neuroscience Abstracts, 1977, 3, 477.

Chance, W. T., White, A. C., Krynock, G. M., \& Rosecrans, J. A. Autoanalgesia: Behaviorally activated antinociception. European Journal of Pharmacology, 1977, 44, 283-284 (a)

Chance, W. T., White, A. C., Kry nock, G. M., \& Rosecrans, J. A. Centrifugal control of nociception: Autoanalgesic mechanisms. Society Neuroscience Abstracts, 1977, 3, 479. (b)

EL-Sobky, A., Dostrovsky, J. O., \& W ALL, P. D. Lack of effect of naloxone on pain perception in humans. Nature, 1976, 263, 783-784.

Evans, W. O. A new technique for the investigation of some analgesic drugs on a reflexive behavior in the rat. Psychopharmacology, '1961, 2, 318-325.

Fratta, W., Yang, H. Y. T., Hong, J., \& Costa, E. Stability of met-enkephalin content in brain structures of morphinedependent or foot shock-stressed rats. Nature, 1977, 268, $452-453$.

Frederickson, R. C. A., Burgis, V., \& Edwards, J. D. Hyperanalgesia induced by naloxone follows diurnal rhythm in responsivity to painful stimuli. Science, 1977, 198, 756-758.

Goldstein, A., Pryor, G. T., Otis, L. S., \& Larsen, F. On the role of endogenous opioid peptides: Failure of naloxone to influence shock escape threshold in the rat. Life Sciences, 1976, 18, 599-604.

Guilleman, R., Vargo, T., Rossier, J., Minick, S., Ling, N., Rivier, C., Vale, W., \& Bloom, F. B-endorphin and adrenocorticotropin are secreted concomitantly by the pituitary gland. Science, 1977, 197, 1367-1369.

Hayes, R. L., Bennett, G. J., Newlon, P., \& Mayer, D. J. Analgesic effects of certain noxious and stressful manipulations of the rat. Society Neuroscience Abstracts, 1976, 2, 1350.

JaCob, J. J., Tremblay, E. C., \& Colombel, M. C. Enhancement of nociceptive reactions by naloxone in mice and rats. Psychopharmacology, 1974, 37, 217-223.

JACQuet, Y. F., \& LAJThA, A. Paradoxical effects after microinjection of morphine in the periacqueductal gray matter in the rat. Science, 1974, 185, 1055-1057.

Lord, J. A. H., W ATERfield, A. A., Hughes, J., \& Kosterlitz, H. W. Endogeneous opioid peptides: Multiple agonists and receptors. Nature, 1977, 267, 495-499.

Madden, J., Akil, H., Patrick, R. L., \& Barchas, J. D. Stress-induced parallel changes in central opioid levels and pain responsiveness in the rat. Nature, 1977, 265, 358-360.

Martin, W. R. Opioid antgonists. Pharmacology Review, 1967, 19, 463-521.

MAYer, D. J.. \& PRICE, D. D. Central nervous system mechanisms of analgesia. Pain, 1976, 2, 379-404.

Oliveras, J. L., Hosobuchi, Y., Redjemi, F., Guilbaud, G., \& Besson, J. M. Opiate antagonist, naloxone, strongly reduces analgesia induced by stimulation of a raphe nucleus (centralis inferior). Brain Research, 1977, 120, 221-229.

Pert, A., \& Walter, M. Comparison between naloxone reversal of morphine and electrical stimulation induced analgesia in the rat mesencephalon. Life Sciences, 1976, 19, 1023-1032.

Price, D. D., Hayes, R. L., Bennett, G. J., Wilcox, G. L., \& MAYER. D. J. Effects of dorsolateral spinal cord lesions on 
narcotic and non-narcotic analgesia in the rat. Society Neuroscience Abstracts, 1976, $2,947$.

Rossier, J., \& French, E. D., Rivier, C., Ling, N., Guilleman, R., \& Bloom, F. E. Foot-shock induced stress increases B-endorphin levels in blood but not brain. Nature, 1977, 270, 618-620.

SELYE, H. The story of the adaptation syndrome. Montreal: Acta, 1952.

Spiaggia, A., Bodnar, R. J., Kelly, D. D., McManus, M. E., \& Glusman, M. Biphasic alterations in nociceptive thresholds after food deprivation. Society Neuroscience Abstracts, 1977. 3, 492.

Yaksh, T. L., Yeung, J. C., \& Rudy, T. A. An inability to antagonize with naloxone the elevated nociceptive thresholds resulting from electrical stimulation of the mesencephalic central gray. Life Sciences, 1976, 18, 1193-1198.

(Received for publication April 24, 1978.) 